\title{
The Design of the Model of Wind Power Integration Based on Thermal Power Peak- shaving
}

\author{
Zhao $\mathrm{Yu}$ \\ Power Grid Research Institute \\ North China Electric Power University \\ Beijing, China \\ e-mail: yu15811415747@163.com \\ Jia Lin \\ Power Grid Research Institute \\ North China Electric Power University \\ Beijing, China \\ e-mail: linchia@126.com
}

\author{
Dayong $\mathrm{Yu}$ \\ State Power Economic Research Institute \\ Liaoning, China \\ e-mail: ydy1970@126.com
}

\author{
Dongxue Li \\ State Power Economic Research Institute \\ Liaoning, China \\ e-mail: ldxztg79@163.com \\ Tong Jiang \\ Power Grid Research Institute \\ North China Electric Power University \\ Beijing, China \\ e-mail: jiangtong@ncepu.edu.cn
}

\begin{abstract}
With the country promoting the power from new energy sources, wind power was attached with great importance gradually. However, there is an existing major problem in the field of wind power, that it is the lack of peak-shaving capacity, which leads the capacity of wind power integration to be limited. For solving the problem of the lack of peak-shaving capacity, the models of "equivalent load" and "equivalent power injection" and the wind power integration model based on thermal power peak-shaving capacity is built in this paper, which takes controlling the capacity of wind power integration reasonably as target. The model can forecast the maximum power of wind power integrated in the power grid in real time. The reasonability of the model is verified by an actual example. Furthermore, for obtaining more social benefits and economic benefits, this paper analyzes wind power control strategies in both cases of conventional peak-shaving and deep peak-shaving. Finally, the paper gets the following conclusion. In the case of conventional peak-shaving, wind power should be controlled reasonably according to the peak-shaving capacity of thermal power. In the case of deep peak-shaving, peakshaving cost should be increased for eliminating the crowding-out effect.
\end{abstract}

Keywords-wind power; wind power integration model; peak-shaving; social benefits; economic benefits

\section{INTRODUCTION}

In recent years, with the rapid development of economy and society, sustainable development and environmental protection are widely concerned [1]. Because of the current technical condition, wind power is the most promising renewable energy with large-scale commercial development potential besides hydropower Wind power integration is not only an effective way to achieve large-scale use of wind energy, but also the best choice for improving environment and achieving sustainable development in electricity

China promotes the development of wind power actively. At the end of 2010, China's total wind power installed capacity reached $44.73 \mathrm{GW}$. And the cumulative installed capacity was more than America's, ranking first in the world [2].

World Wind Energy Report 2010 pointed out that in some countries and regions, wind energy had become its one of the most important source of power [3]. Several countries with the largest share are: Denmark 21\%, Portugal $18 \%$, Spain $16 \%$, and Germany $9 \%$. China's wind power supply is very low proportion, which is account for only $1.2 \%$ of the total generating capacity [4]. One of the main reasons is the lack of peak-shaving capacity, which results that in some specific operating conditions, increasing the capacity of wind power integration does not further reduce whole system energy consumption and corresponding greenhouse gases and pollution emissions decline [5]. Therefore, the purpose of this paper is to build a model that can control the wind power integrated in the power grid in real time to improve the capacity of wind power integration according the peak-shaving capacity as far as possible. 


\section{THE ANALYSIS OF THE LACK OF PEAK-SHAVING CAPACITY}

The output power of Wind farm depends on the natural wind. It has the features of volatility, uncertainty and intermittency. So wind power integration has to be completed by the means of increasing the capacity of peakpeaking. With the increase of wind power installed capacity, the impact of wind power cannot be ignored, in the aspects of the voltage stability and power quality [6, 7].

China's wind power is mainly concentrated in the northeast area, whose capacity of wind power integration accounts for $87 \%$ of the total capacity of wind power integration of whole country. However, the features of local power grid, power supply and load are not considered in detail because of the short period planning and construction of wind power, which results in the difficulties of wind power integration in this area. The energy structure of the northeast region is coal-based and lack of the power supply with flexible adjustment ability [8]. For example, the proportion of thermal power is more than $80 \%$. But the proportion of power supply with flexible adjustment ability is just about $7.8 \%$. The power grid cannot effectively balance the impact of fluctuation of wind power. So wind power integration is severely constrained because that it has difficulty in peak-shaving for a long time. Along with gradually increasing scale of wind power development, peak-shaving is pretty hard especially in the winter, when it is not only the heating period of thermal power and the dry season of hydropower, but also the period of wind power flourishing $[9,10]$.

\section{THE BULIDING OF THE MODEL OF WIND POWER INTEGRATION}

\section{A. The Models of "Equivalent Load" and "Equivalent Power Injection"}

There are rich wind resources in the northeast area of China, whose means of peak-shaving is mainly thermal power peak-shaving. Its capacity of peak-shaving is insufficient especially in the winter. So the phenomena of "abandoning wind" and "power rationing" are particularly serious in winter period because that heating units occupies a higher proportion in the operating units, which causes the capacity of downward peak-shaving to be limited.

If the prediction was not included in the dispatch plan, the reliable electricity contribution of wind power would be lost. Furthermore excess wind power may be integrated in the gird, which can result in the decline of average load rate of conventional thermal power units, the increase in coal consumption and even the increase of possibility of "abandoning wind" in the low load periods.

If the prediction of wind power was included in the power grid dispatch planning, by grasping of the trends of wind power output, the combination modes of units could be optimized, load rate of conventional units could be improved, and coal consumption of the whole gird could be reduced, which attains the goal of improving the integrated operational benefits of system.

In this paper, the model of rationally planning the amount of wind power integration is built for the power grid with thermal power peak-shaving. For real-time dispatch of wind power, the model must be based on load forecasting and wind power forecasting [11].

For studying the impact of thermal power peak-shaving capacity on wind power alone, this paper proposes a concept of "equivalent load". The "equivalent load" is combined with actual load power and the rated output of peak-shaving units such as hydroelectric generating set and pumped storage units. The "equivalent load" is presented as following (1).

$$
\mathrm{P}^{\prime}=\mathrm{P}-\sum \mathrm{P}_{\mathrm{w}}-\sum \mathrm{P}_{\mathrm{s}}
$$

In the equation, $\mathrm{P}$ ' is the "equivalent load" presented in this paper, $\mathrm{P}$ is the actual load power of gird, $\mathrm{P}_{\mathrm{w}}$ is rated power of hydroelectric generating set, and $\mathrm{P}_{\mathrm{s}}$ is the rated power of pumped storage units. Using actual data of a province, actual load power curve and the "equivalent load" power curve can be presented as following Fig .1.

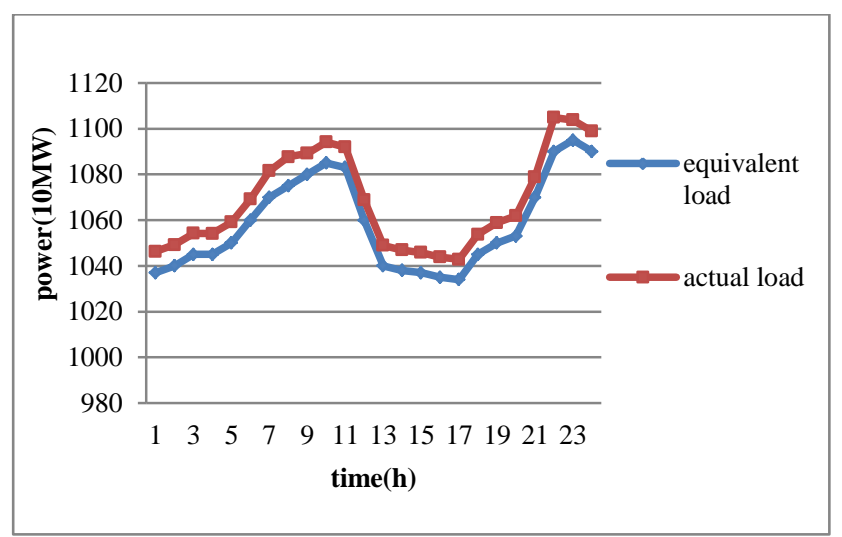

Figure 1. The power curves of "equivalent load" and actual load

The actual situation shows that the main power injection of the province includes the system tie-line power and the power of hydroelectric generating set and thermal power. The concept of "equivalent power injection" can be proposed because that the power of hydroelectric generating set is included in "equivalent load". The "equivalent power injection" includes thermal and power system tie-line power. The system tie-line power has no ability of peak-shaving, but thermal power undertakes the primary task of peak-shaving. Therefore, in consideration of thermal power consumption rate, loss rate of transmission and loss rate of tie-line, the mathematical model of the maximum power and the minimum power of the "equivalent power injection" is as following (2) and (3).

$$
\begin{gathered}
\mathrm{P}_{\max }=\left(1-\delta_{\mathrm{g}}-\delta_{1}\right) \times \sum \mathrm{P}_{\mathrm{g}}+\left(1-\delta_{\text {line }}\right) \times \mathrm{P}_{\text {line.max }} \\
\mathrm{P}_{\min }=\left(1-\delta_{\mathrm{g}}-\delta_{1}\right) \times \sum\left(\mathrm{C}_{\mathrm{g}} \times \mathrm{P}_{\mathrm{g}}\right)+\left(1-\delta_{\text {line }}\right) \times \mathrm{P}_{\text {line.min }}
\end{gathered}
$$

In the two equations, $\mathrm{P}_{\max }$ and $\mathrm{P}_{\min }$ are the maximum power and the minimum power of the "equivalent power injection", $\mathrm{P}_{\mathrm{g}}$ is the output power of thermal power units, $\mathrm{P}_{\text {line.max }}$ and $\mathrm{P}_{\text {line.min }}$ are the system tie-line power at the time of peak load and valley load, $\delta_{\mathrm{g}}$ is power consumption rate of thermal power plants, $\delta_{1}$ is loss rate of transmission, $\delta_{\text {line }}$ is loss rate of tie-line, $\mathrm{C}_{\mathrm{g}}$ is the factor of 
minimum technical output of peak-shaving units, which determines the peak-shaving capacity of thermal power.

\section{B. The Model in the Case of Conventional Peak-shaving}

The maximum wind power integrated into gird can be presented on the basis of the above in the case of conventional peak-shaving. Because of the limit of minimum power of thermal power integrated in the power grid, every moment the maximum wind power integrated into gird is equal to the difference between "equivalent load" of corresponding moments and the minimum power of the "equivalent power injection".

$$
\mathrm{P}_{\text {wind.max }}=\left(\mathrm{P}^{\prime}-\mathrm{P}_{\min }\right) /\left(1-\delta_{\mathrm{w}}\right)
$$

In the equation, $\mathrm{P}_{\text {wind.max }}$ is the maximum wind power integrated in the power grid, $\delta_{w}$ is the power consumption rate of wind farm. If the wind power was less than $\mathrm{P}_{\text {wind.max }}$, the total wind power could be integrated into gird. If the wind power was larger than $\mathrm{P}_{\text {wind.max }}$, the wind power integrated in the power grid should be controlled by abandoning the part that is larger than $\mathrm{P}_{\text {wind.max }}$.

\section{The Model in the Case of Deep Peak-shaving}

In the case of deep peak-shaving, the crowding-out effect [12] have to be taken into account.

When the capacity of down peak-shaving is exhausted, thermal power units will be forced to execute deep peakshaving (unconventional peak-shaving) although the power grid can integrate more wind power by further reducing the output of peak-shaving units to get more downward spare capacity. In addition, thermal power units will be forced to operate with oil to ensure stable burning. It results in not only the decline of efficiency of the power generation units and significant increase in coal consumption rate, but also the secondary burning of the sticky pulverized coal, which threatens the safe operation of the boiler.

The crowding-out effect may reduce the social benefits of wind power because that additional wind power causes increase in system-wide energy consumption, greenhouse gases and pollutant emissions. Therefore, the crowdingout effect need to be eliminated by improving the cost of peak-shaving and increasing energy storage device in order to ensure that social and comprehensive benefit is greater than zero.

The generating cost without wind power is combined with resource $\operatorname{cost} C_{r}$ and environmental cost $C_{e}$ as (5).

$$
\mathrm{C}=\mathrm{C}_{\mathrm{r}}+\mathrm{C}_{\mathrm{e}}
$$

When wind power is integrated in the power grid, the generating cost is combined with resource cost $\mathrm{C}_{\mathrm{r}}^{\prime}$ and environmental $\cos t \mathrm{C}_{\mathrm{e}}^{\prime}$ and peak-shaving $\operatorname{cost} \mathrm{C}_{\mathrm{p}}$, as (6).

$$
C^{\prime}=C_{r}^{\prime}+C_{e}^{\prime}+C_{p}
$$

Then analyze the difference $\Delta \mathrm{C}$ between $\mathrm{C}$ and $\mathrm{C}^{\prime}$ supposing that other factors are constant, such as generated energy and transmission loss.

$$
\Delta \mathrm{C}=\mathrm{C}-\mathrm{C}^{\prime}
$$

If $\Delta \mathrm{C}>0$, the amount of wind power integrated in the power grid could be increased because that the comprehensive benefit is greater than zero. If $\Delta \mathrm{C}<0$, the amount of wind power integrated in the power grid should be reduced to make the comprehensive benefit turn to be greater than zero.

\section{THE ANALYSIS OF EXAMPLE}

The actual data are used to test the model. The parameters of (2), (3) and (4) are shown in the following TABLE I.

TABLE I THE VALUE OF THE RELEVANT PARAMETER

\begin{tabular}{cccc}
\hline Parameter & $\delta_{\mathrm{g}}+\delta_{\mathrm{l}}$ & $\delta_{\text {line }}$ & $\delta_{\mathrm{w}}$ \\
\hline Value & $8 \%$ & $1.6 \%$ & $2 \%$ \\
\hline
\end{tabular}

The calculation of (2) shows that the minimum power of the "equivalent power injection" is $6900 \mathrm{MW}$ due to the limit of the minimum power of thermal power integrated in the power grid. So the maximum wind power integrated in the power grid is equal to the difference between "equivalent load" and the calculated result. The curve of the maximum wind power integrated in the power grid is shown as the Fig. 2 .

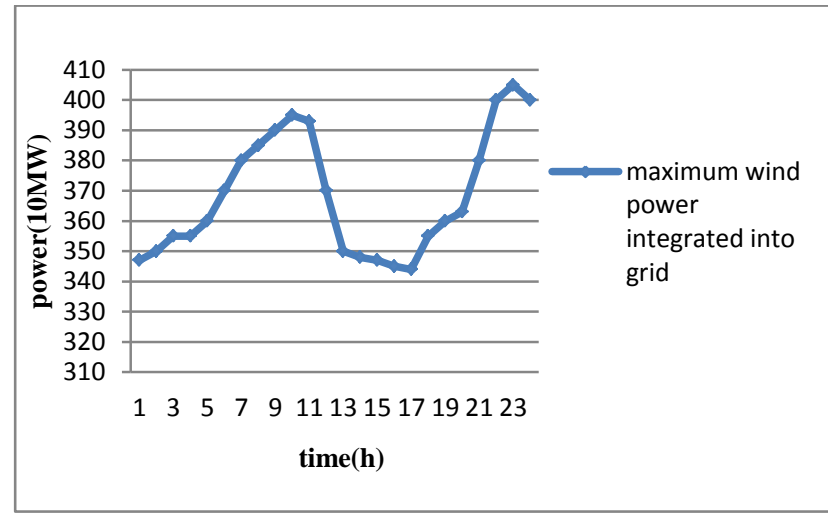

Figure 1. The curve of the maximum wind power integrated in the grid

Then above curve is compared with the curve of actual wind power, which is shown as the Fig.3.

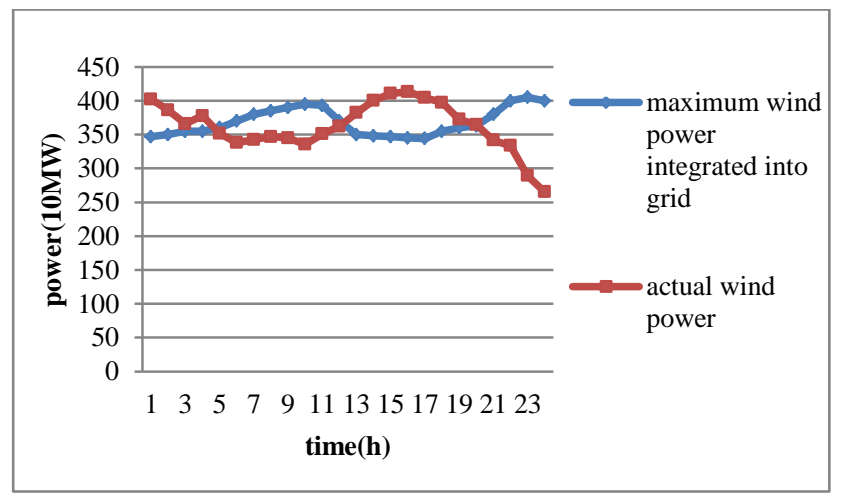

Figure 2. The curve of the maximum wind power and actual wind power

The result can be seen from the Fig .3, that the actual wind power has exceeded the maximum wind power 
integrated in the power grid from 1:00 to 5:00 and 12:00 to 20:00. Therefore, in the case of conventional peak-shaving, actual wind power should be controlled by abandoning wind reasonably in those periods.

In fact, if wind power had to be used as much as possible for obtaining more social benefits, the additional wind power could be integrated in the power grid by improving the cost of peak-shaving. In that case, minimum capacity of thermal power units integrated in the power gird has to be guaranteed. That is to say, the power gird must include enough thermal power to ensure stable operation. The generating cost of wind farm is low because of taking no account of the construction cost of wind farm. So the additional cost of peak-shaving can be borne by the wind farm. However comprehensive benefit (the algebraic sum of social benefits and economic benefits) has to be concerned. That is, if the comprehensive benefit is less than or equal to zero, the superfluous wind power should be eliminated.

\section{CONCLUSION}

This paper analyzes the impact on wind power integration, caused by the lack of peak-shaving capacity, and gets the conclusion that lack of peak-shaving capacity is the main reason for bottleneck problem of wind power integration.

In addition, the paper proposes a model of wind power integration based on thermal power peak-shaving, which can completes the real-time dispatch of wind power according to the prediction of the models of "equivalent load" and "equivalent power injection". Then the rationality of the model is verified by the actual example. Conclusions can be seen from the calculated result, that wind power prediction can improve use ratio of wind power and reduce the bad effect of volatility and reverse peak-shaving on the power grid.

Finally, through discussion of wind power control strategies in both cases of conventional peak-shaving and deep peak-shaving. The paper draws the following conclusions. In the case of conventional peak-shaving, wind power should be controlled reasonably according to the peak-shaving capacity of thermal power. In addition, it is proposed that the peak-shaving cost should be increased for eliminating the crowding-out effect, when the deep peak-shaving is taken into account. At the same time, the change of conventional should be concerned, for adjusting the wind power timely to avoid causing crowding-out effect.

\section{REFERENCES}

[1] Kang Chong-qing, Chen Qi-xin and Xia Qing, "Prospects of lowcarbon electricity", Power System Technology, 2009. Vol.33(2): 17.

[2] Li Jun-feng, Gao Hu and Shi Peng-fei, China Wind Power Report 2010. Haikou: Hainan Publishing House, 2008. 6-7.

[3] J. Driesen and R. Belmans, Distributed Generation: challenges and possible solutions, IEEE Power Engineering Society General Meeting, Montreal, 15-17. Canada, 2006. June 18-22.

[4] Li Jun-feng, Gao Hu \& Shi Peng-fei, China Wind Power Report 2010. Haikou: Hainan Publishing House, 2010. 6-7.

[5] E. Denny, G. Bryans, J. Fitz and M. O’Malley, "A quanti-tative analysis of the net benefits of grid integrated wind" J. IEEE Transactions on Power Systems. 2007.22, 1-8.

[6] I. S. Naser, A. Garba, O. Anaya-Lara and K. L. Lo, "Volt-age stability of transmission network with different penetration levels of wind generation" In Universities Power Engineering Conference (UPEC), 2010 45th International. IEEE. 1-5

[7] Y. Chi, Y. Liu, W. Wang and H. Dai, "Voltage stability analysis of wind farm integration into transmission network". in Power System Technology, 2006. PowerCon 2006. Inter-national Conference. IEEE. 1-7.

[8] X. Kang. et al. "Balance of power: Toward a more environmentally friendly, efficient and effective integration of energy systems" in China. J. Power and Energy Magazine. IEEE. 2013. 11(5), 56-64.

[9] Liu De-wei, Huang Yue-hui, Wang Wei-sheng and Guo Jian-bo, "Analysis of capacity of wind power integration in provincial system considering the constraints of peak-shaving and transmission", Automation of Electric Power Systems, 2011. (22).

[10] H. Li, Z. Lu, Y. Qiao and W. Wang, Risk assessment of power system with high penetration of wind power consid-ering negative peak shaving and extreme weather conditions. In PES General Meeting Conference \& Exposition, 2014 IEEE. 1-5.

[11] Zhang Li-ying, Ye Yan-lu \& Xin Yao-zhong, "Problems and measures of power grid accommodating large scale wind power", Proceedings of the CSEE, 2010. (25).

[12] Yan Gan-gui, Liu Hong-zhe, Mu Gang and Yuan Tian-fen, "Crowding-out effect of wind power under special condition and comprehensive evaluation on energy-Saving and emission reduction benefits of wind power generation", Power System Technology, 2012. (4). 